Vegueta. Anuario de la Facultad de Geografía e Historia

22 (1), 2022, 57-78

eISSN: $2341-1112$

https://doi.org/10.51349/veg.2022.1.04

\title{
Guerra de la Independencia e historia digital: dos proyectos de la Universidad de Alicante
}

\author{
The Peninsular War and Digital History: Two Projects at the University of \\ Alicante
}

\author{
Rafael Zurita-Aldeguer \\ Universidad de Alicante \\ Departamento de Humanidades Contemporáneas \\ https:/ / orcid.org/0000-0003-4075-426 \\ rafael.zurita@ua.es
}

Recibido: 29/10/2021; Revisado: 15/12/2021; Aceptado: 29/12/2021

\begin{abstract}
Resumen
El artículo defiende el interés que tiene la historia digital para la construcción del relato histórico, la divulgación y la transferencia de conocimiento. Para ello, explica el origen y desarrollo, así como los resultados, de dos proyectos de investigación que se sustentan en el diseño y la creación de webs semánticas. El contenido histórico de las webs es la guerra contra Napoleón en España. El primer proyecto -Guerra e historia pública- se centra en la Comunidad Valenciana y el segundo en España; este último -Paisajes de guerra-, además, plantea la puesta en valor de los paisajes culturales relacionados con los campos de batalla.
\end{abstract}

Palabras clave: Historia digital, historia pública, guerra de la Independencia española.

\begin{abstract}
This article argues for the importance of digital history in the construction of historical narrative, dissemination and knowledge transfer. To this end, it describes the origin, development and results of two research projects based on the design and creation of semantic websites. The historical content of the websites relates to the war against Napoleon in Spain. The first project, War and Public History, focuses on the Valencian Community, while the second, Landscapes of War, focuses more broadly on Spain. This latter also proposes the revaluation of cultural landscapes related to battlefields.
\end{abstract}

Keywords: Digital History, Public History, Peninsular War. 


\section{INTRODUCCIÓN}

La historia digital ha experimentado, desde comienzos del siglo xXI, un notable avance, aunque en el caso español parece moverse a una velocidad lenta (Pons y Eiroa, 2018: 13-18). Es posible que ello sea debido a que, en el ámbito académico, hay pocas voces que apoyan este campo de trabajo o no suscitan el suficiente debate. Al respecto, puedo ofrecer un dato, quizá significativo, sobre la cuestión. En el XV Congreso de la Asociación de Historia Contemporánea, celebrado en Córdoba en septiembre de 2021, hubo 46 talleres y 4 mesas redondas. La historia digital se trató con detalle sólo en dos talleres: Archivos, Documentos y Fuentes Digitales de la Historia: Herramientas, Métodos y Técnicas de Investigación; e Historia pública: desafíos y experiencias. ${ }^{1}$ Pues bien, en este artículo voy a explicar la apuesta digital que suponen los proyectos de investigación que he dirigido desde la Universidad de Alicante y su aportación al tema de la guerra de la Independencia española.

Entre 2017 y 2021, dos proyectos de historia digital recibieron la financiación de la Generalitat Valenciana y de la Fundación BBVA: Guerra e Historia Pública y Paisajes de guerra, respectivamente. El primero está centrado en la Comunidad Valenciana, mientras que el segundo es de ámbito nacional; uno plantea un enfoque de historia social de la guerra, para conocer y comprender la vida de hombres y mujeres, civiles y militares, entre 1808 y 1814; el segundo dirige su atención hacia el patrimonio vinculado con los paisajes culturales de los campos de batalla. Ambos se sustentan en plataformas digitales concebidas como webs semánticas, en equipos multidisciplinares de investigadores y proporcionan transferencia de conocimiento.

Los objetivos del artículo son fundamentalmente dos: por un lado, mostrarélas características principales de los proyectos citados y explicaré el método seguido para su desarrollo; por otra parte, subrayaré sus elementos más destacados y su importancia para la divulgación y la transferencia de conocimiento.

\section{HISTORIA DIGITAL}

Resulta obvio decir que, hoy día, las tecnologías digitales juegan un papel importante en el trabajo del historiador, aunque sean utilizadas por la mayoría, fundamentalmente, para la búsqueda y consulta de fuentes y bibliografía. En realidad, la historia digital supone nuevas formas de trabajo con el texto y diferentes modos de comunicar la investigación. Se trata de un proceso con creciente impacto, pues cambia poco a poco la forma de la investigación y la docencia, supone una propuesta para el examen y la representación del pasado y, además, anima a los usuarios a establecer sus propias conexiones para la lectura de un relato histórico (NOIRET, 2013: 155-190; PONS, 2013: 62-65 y 287-297).

1 Programa del Congreso, disponible en https://congresoahcordoba2020.es/programa/ [Consulta: $10-9-202+1$. 


\subsection{Implicaciones teóricas y metodológicas}

Pons señaló en 2013 que las humanidades digitales estaban «en tierra de nadie», es decir, ocupaban un espacio poco definido entre el conocimiento impreso, fundamentalmente académico, y el espacio digital marcado por un «desorden» que generaba incertidumbres (PONS, 2013: 40). Así, la primera cuestión que plantearon los especialistas, a comienzos del siglo XxI, fue una definición basada en las características de ese nuevo campo del conocimiento. El Manifiesto de 2010, de la Conferencia internacional THAT Camp, calificó las Humanidades digitales como una «transdisciplina» puesto que vehicula los métodos, sistemas y perspectivas heurísticas vinculadas a lo digital. ${ }^{2}$ Sin embargo, este enunciado no tiene un apoyo unánime, ya que otros historiadores niegan que la historia digital sea una disciplina; señalan que no cuenta todavía con un marco teórico desarrollado, aunque, en lo referido al método, presente diversas formas, que pueden ser consideradas válidas, de «hacer historia» en la red.

Resulta evidente que el universo internet diluye las jerarquías en la producción de conocimiento y requiere filtros y análisis, pues no distingue entre lo verdadero y lo falso, lo importante y lo secundario. Y más si tenemos en cuenta las posibilidades que ofrecen los medios digitales: capacidad, accesibilidad, flexibilidad, diversidad, interactividad e hipertextualidad. En realidad, para afrontar las implicaciones teóricas y metodológicas de la historia digital es pertinente centrar el foco en tres cuestiones: la autoría, la audiencia y el efecto que produce lo digital en el historiador a la hora de abordar un problema histórico.

La cuestión de la autoría es una de las más problemáticas de la historia digital. Junto a las plataformas que son resultado de proyectos de investigación universitarios o los blogs didácticos promovidos por el profesorado, encontramos infinidad de blogs/webs o perfiles en las redes sociales creados por aficionados a la historia. En unos casos, estos hacen una aportación positiva mediante la difusión de contenidos basados en referencias, pero también pueden generar espacios de confusión, cuando no de manipulación histórica. Esta cuestión, a su vez, entronca con uno de los aspectos clave de la historia pública que supone, entre otros aspectos, la autoría compartida, sobre todo en lo referido a la generación de recursos y fuentes históricas (AsHTON y TRAPEZNIK, 2019).

Por otra parte, si nos fijamos en la audiencia de la historia digital, no hay que pensar únicamente en lectores pasivos, en las «visitas» de una web. Los espacios webs más dinámicos potencian la interactividad, que proporciona múltiples formas de diálogo y feedback entre profesionales/no profesionales, estudiantes/ profesores, y métodos para compartir y colaborar en el trabajo histórico (BOCANEGRA, 2016). Esto lleva a un concepto muy interesante de la cultura digital: la creación de una comunidad, es decir, un grupo de personas que no sólo están interesadas por el contenido y las fuentes de un tema, sino que también pueden participar en la potenciación de una web con el uso de los recursos que esta ofrece e, incluso, con la creación de nuevos recursos. Así, el éxito de una web se debería medir no tanto por «cuantos» visitantes recibe, sino por «cómo» la utilizan (COHEN y RosENZWEIG, 2006: 141-159).

Sin duda, es fundamental que una web de historia entable un diálogo con archiveros, bibliotecarios, especialistas en patrimonio e informáticos y que, con

2 THAT Camp Paris, disponible en https:/ /tcp.hypotheses.org/411 [Consulta: 5-9-2021]. 
ello, muestre el carácter interdisciplinar de la historia digital (PRADES, 2016). Esto puede influir en el historiador a la hora de analizar un problema y de «narrarlo». Así, el hipertexto implica diversas formas de «leer» una web y un cambio de paradigma en lo referido a la linealidad o la jerarquía de los contenidos; plantea, en definitiva, la posibilidad de una narración abierta. De este modo, las humanidades digitales se convierten en una práctica de representación y, al mismo tiempo, en un modelo de razonamiento (WELLER, 2013: 200-202).

Quizá cabe preguntarse si, en el campo de la historia, la web, el blog y las redes sociales son formas válidas, como las publicaciones impresas, para generar y transferir conocimiento; o si, en realidad, su aceptación académica debe quedar limitada a eficaces repositorios de documentos o de contenidos, ya elaborados previamente con su correspondiente aparato crítico. Así, resulta evidente la necesidad de un debate que permita establecer «indicios de calidad» para valorar su aportación científica e impacto. Por el momento, los especialistas distinguen cuatro categorías básicas dentro de las webs de historia: herramientas de información y comunicación, fuentes, escritura y enseñanza de la historia (COHEN y RosenZWEIG, 2006: 1-17).

\subsection{Las referencias en el campo de la Historia Contemporánea}

Dos centros fueron pioneros en el surgimiento de las humanidades digitales y han sido referentes mundiales en su desarrollo: el Departamento de Digital Humanities del King's College de Londres (1992) y el Roy Rosenzweig Center for History and New Media's, creado en la Universidad George Mason (Virginia, 1994). Se trata de potentes instituciones que cuentan con subvenciones públicas y privadas. ${ }^{3}$

De acuerdo con los especialistas, cabe destacar tres notas distintivas en los proyectos de historia digital más relevantes: su carácter interdisciplinar, el trabajo colaborativo y la vocación de proyección pública. Es el caso de uno de los proyectos más antiguos: The Valley of Shadow (Universidad de Virginia, 19932007) realizó un interesante recorrido por dos condados, uno nordista y otro sudista, antes, durante y después de la Guerra civil norteamericana. En la web se pueden consultar cartas, periódicos, mapas, fotos y bases de datos y fue uno de los primeros repositorios de documentos que permitía la consulta cronológica y temática a través de una rica y variada colección de fuentes de ámbito local. Basó su desarrollo en una eficaz tarea de colaboración a distintos niveles, entre profesorado, alumnado, archiveros y particulares. ${ }^{4}$ Se trata de una forma de crowdsourcing, una práctica participativa característica de la historia pública digital. Ello implica la producción de contenidos en red por parte de un público amplio. Otro ejemplo destacado, más reciente y todavía abierto, es Europeana 1914-1918.

Quiero señalar tres proyectos surgidos en España, centrados en la Historia

3 Departament of Digital Humanities, disponible en https://www.kcl.ac.uk/ddh y Roy Rosenzweig Center for History and New Media's, disponible en https://rrchnm.org/what-we-do/ [Consulta: 1-9-2021].

4 The Valley of Shadow, disponible en http://valley.lib.virginia.edu [Consulta: 19-9-2021].

5Europeana 1914-1918, disponibleen https:/ / www.europeana.eu/es/collections/topic/83-1914-1918 [Consulta: 19-9-2021. 
Contemporánea y que cuentan ya con un largo recorrido: Memoria digital de Elche (Universidad Miguel Hernández de Elche, 2009), dirigido por Miguel Ors, recopila diversos documentos sonoros, audiovisuales y biografías y se nutre, fundamentalmente, de las aportaciones de los particulares. ${ }^{6}$ En segundo lugar, la plataforma digital e-xiliad@s. España en una maleta es un proyecto de investigación interactivo que «recopila y agrupa la memoria del exilio, especialmente aquella memoria femenina». A partir de la Tesis de Doctorado de la directora del proyecto, Lidia Bocanegra, la web sigue completando información con las referencias y documentos de los familiares del exilio. Así, en su página de inicio podemos leer: «Si eres un exiliado o has tenido contacto con el exilio de cualquier forma (como retornado, hijo, nieto o amigo) tu memoria nos interesa. Incluso si eres un estudiante del exilio republicano». Para ello, han creado un formulario online donde se puede responder a una serie de cuestiones generales. Este proyecto ganó el premio Humanidades Digitales Hispánicas 2020 a la mejor participación y presencia en redes sociales. ${ }^{7}$ Por último, HISMEDI es el acrónimo de Historia, Memoria y Sociedad digital. Nuevas formas de transmisión del pasado (Universidad Carlos III, 2016) y está dirigido por Matilde Eiroa. Aquí se analiza la presencia y representación de la Historia y la Memoria en Internet en el último decenio, en lo referido a la Guerra Civil, el Franquismo y la Transición política a la democracia. Entiende por ello «tanto el tipo de acontecimiento histórico divulgado en los formatos digitales, como su cobertura, la interpretación que se ofrece de los mismos $y$, en consecuencia, el conocimiento histórico que generan en una sociedad conformada por nuevos públicos que cada vez participa, colabora y se informa más a través de la Red». Y plantea varias preguntas acerca de la presencia de la historia reciente de España en internet, de forma especial acerca del papel que tienen los historiadores en la nueva transmisión de la ciencia histórica con la sociedad. ${ }^{8}$

Observando estos ejemplos, y otros desarrollados en Europa y Estados Unidos, es evidente que las humanidades digitales suponen nuevas formas de abordar el texto y la imagen, la colaboración interdisciplinar, el uso de software libre, la utilización de las redes sociales para compartir y debatir temas humanísticos y un mayor acercamiento académico a la sociedad (BOCANEGRA, 2016; NoIret, 2018a). Como señala Noiret, el «giro digital» tiene una doble implicación con respecto a la relación del público con la historia: por un lado, los historiadores comparten su autoridad con los crowdsourcers a través del trabajo colaborativo desarrollado en las webs. La denominada «co-creación», también en las redes sociales, cobra impulso paulatinamente (Bocanegra et al., 2017). Por otra parte, prolifera «un público perturbador que cuestiona a los historiadores profesionales y genera incertidumbres sobre el futuro de la historiografía tradicional y las narrativas del pasado para públicos diversos». Estas iniciativas particulares proceden de personas interesadas por la historia, sin formación específica o que no siguen criterios científicos, pero también surgen entre graduados o máster en Historia que no trabajan en las universidades. Por ello, las narrativas de la historia digital requieren que los métodos y códigos profesionales se reinterpreten y cabe

6 Memoria digital de Elche, disponible en http:/ / www.elche.me [Consulta: 19-9-2021].

7 e-xiliad@s. España en una maleta, disponible en https://exiliadosrepublicanos.info/es/proyecto [Consulta: 19-9-2021].

8 HISMEDI. Historia, Memoria y Sociedad digital. Nuevas formas de transmisión del pasado disponible en https://uc3m.libguides.com/Hismedi [Consulta: 20-9-2021]. 
preguntarse si debemos revisar profundamente la relación actual con la historia y la memoria (NoIRET, 2018b: 111-124). En cualquier caso, parece cierto que estas mutaciones crean nuevas oportunidades de trabajo, de investigación y de difusión del conocimiento histórico (SALVATORI, 2017: 57-94).

Este sucinto recorrido por las características de la historia digital debellevarnos a romper con la tradicional identificación de este campo como un mero repositorio de documentos digitalizados o como un espacio destinado fundamentalmente a la divulgación de los proyectos de investigación. El universo digital también es el lugar donde experimentar modalidades alternativas de investigación histórica, crear y compartir contenidos históricos y, desde luego, realizar transferencia del conocimiento (PACI, 2019: 19-23).

\section{EL PROYECTO GUERRA E HISTORIA PÚBLICA}

Mi experiencia con la historia digital es reciente y positiva. El primer proyecto de investigación -Guerra e historia pública- tiene su raíz en la convergencia de dos líneas de trabajo iniciadas hace siete años: un libro impreso y una comunicación en un Congreso. En 2015, publiqué Suchet en España. Guerra y sociedad en las tierras del sur valenciano (1812-1814). Era resultado de una investigación que obtuvo el «Premio Ejército 2014» del Ministerio de Defensa. El libro está planteado desde el enfoque de la historia social de la guerra. Por ello, analiza cómo los ejércitos y sus operaciones determinaron la vida de las personas y el curso de las instituciones. Y lo hace en un espacio, el sur valenciano, que se convirtió en una auténtica línea del frente durante los años finales del conflicto peninsular. Así, presta atención a los mecanismos de ocupación del ejército comandado por el mariscal Suchet y a las respuestas que dieron, ante ella, los combatientes y los no combatientes. Para ello, utilicé diversas fuentes españolas, francesas e inglesas y combiné el rigor académico con el tono divulgativo, gracias a la inserción de cartografía, biografías, figuras y cuadros de texto, que ampliaban diversos temas expuestos en el cuerpo principal de la narración (ZURITA, 2015).

El segundo elemento fue la comunicación presentada en el XIII Congreso de la Asociación de Historia Contemporánea (La Historia, lost in translation? Albacete, septiembre de 2016). Mi texto se discutió en el taller "Ciencia historiográfica, transferencia del conocimiento y humanidades digitales: metodologías de investigación, documentación digital y revistas de historia» (AlíA et al., 2017: 3.1333.204). Bajo el título Guerra e Historia pública. Una propuesta de web 2.0, planteé una cuestión u opción metodológica que, hasta entonces, habían (han) tenido poco recorrido en el ámbito de la historiografía española de la época contemporánea: la denominada «Historia pública» y su relación con la «Historia digital». Centrado en el tema de la guerra de la Independencia en la Comunidad Valenciana, mi propósito era la creación de una web que tendría varios objetivos: la generación de un espacio digital regido por el rigor en el tratamiento de los contenidos, la transferencia de conocimiento hacia la sociedad, la didáctica de la historia, la promoción de formas de colaboración/participación en creación de contenidos históricos y, por último, la divulgación de la comprensión de un problema del pasado que se plantea en la actualidad, como es la guerra, sus efectos y la imagen que se proyecta de la misma.

En consecuencia, en los últimos años, he trabajado en estas dos líneas 
complementarias, la investigación básica sobre la historia social de la guerra de 1808-1814 y la transferencia de conocimiento relacionada con ella. A la altura de 2022, contamos ya con una plataforma digital inteligente sobre la guerra en Valencia. Una web que se convierte en un punto de convergencia con vocación de largo recorrido. ${ }^{9}$ La actualización y mantenimiento de la web, desde el punto de vista informático, es posible gracias a la colaboración entre el Departamento de Humanidades Contemporáneas y la Cátedra Santander de Transformación Digital de la Universidad de Alicante. ${ }^{10}$ En lo referido a los contenidos históricos sobre la guerra de 1808-1814 en territorio valenciano, la potencialidad de crecimiento y de transferencia del conocimiento es enorme.

\subsection{La web semántica}

Una plataforma digital inteligente o web semántica es el soporte de este proyecto de investigación. La web conforma un espacio regido por la evaluación científica de los contenidos y la promoción de su buen uso y promueve, al mismo tiempo, formas de participación de carácter colectivo. Con ello, establece un ámbito de convergencia entre el trabajo académico -en todos los niveles educativos-, los profesionales que velan por la conservación del patrimonio, la administración local y las iniciativas ciudadanas (VILLAGRÁ y LóPEZ JAVALOYES, 2020).

La web ha cambiado profundamente la forma en la que nos comunicamos y realizamos nuestro trabajo. En este momento, caminamos hacia plataformas «inteligentes» que proponen superar las limitaciones de la web actual, generadas por la sobrecarga de información y la excesiva diversidad de fuentes de datos, con el consiguiente problema de interoperabilidad. Frente a la web actual, con una semántica implícita, el crecimiento caótico de recursos y la ausencia de una organización clara, esta nueva plataforma, denominada web semántica, propone clasificar, organizar y etiquetar los recursos con semántica explícita procesable por máquinas. ${ }^{11}$

La web semántica mantiene los principios de éxito de la web actual, como descentralización, compartición, compatibilidad y máxima facilidad de acceso. Además, rescata la noción de ontología con el objetivo de poner de acuerdo las tres entidades que intervienen en la construcción y aprovechamiento de la web: usuarios, desarrolladores y programas. Una ontología, como jerarquía de conceptos con atributos y relaciones, proporciona un vocabulario para describir un dominio y pone el acento en la compartición del conocimiento y el consenso en la representación de éste. ${ }^{12}$

En la actualidad, muchas plataformas que ofrecen recursos de historia o memoria digital son meros repositorios de contenidos o clasificadores de información. En ellas, solo es posible consultar o descargar documentación. Por

9 Guerra e historia pública, disponible en https://www.guerra-historia-publica.es/ [Consulta: 1-92021].

10 Cátedra Santander de Transformación digital de la Universidad de Alicante, disponible en https:// catedra-transformacion-digital.ua.es/ [Consulta: 1-9-2021].

11 World Wide Web Consortium disponible en https://www.w3c.es/Divulgacion/GuiasBreves/ [Consulta: 15-9-2021].

12 SCRIBD. Historia de la web semántica disponible en https://es.scribd.com/doc/52433211/ Historia-de-La-web-semantica-1 [Consulta: 15-9-2021]. 
eso, para avanzar hacia una web más inteligente, es necesario revisar la forma en que los datos se almacenan, gestionan y recuperan. Hasta hace un tiempo, se pensaba que la inteligencia estaba en los algoritmos que manejaban los datos. Sin embargo, en la actualidad, casi todos los investigadores coinciden en que la inteligencia reside más bien en los datos; es decir, si los datos proporcionan la información adecuada, será posible construir sistemas más inteligentes a partir de aquellos. Esto implica dotar a los datos de significado, lo que se denomina datos semánticos, y utilizar las tecnologías de la información para ello. Se entiende que las tecnologías para la web semántica usan lenguajes formales para definir conceptos, personas, lugares o cualquier otro tipo de entidad, de forma que una máquina pueda diferenciar las expresiones puramente humanas del conocimiento subyacente a éstas (MorA et al., 2015).

Así, por ejemplo, en un entorno de conocimiento relacionado con la historia se pueden identificar entidades como Personaje, Lugar, Documento, Bien material, Iconografía o Hecho, y relaciones como las que establecieron determinados personajes con un lugar, los hechos que acaecieron en un espacio determinado, los monumentos cercanos a una localización geográfica o vinculados con un personaje, los documentos relacionados con un personaje, un lugar o un hecho... Estas entidades y sus relaciones se formalizarían a través de una ontología y, en todo ello, las etiquetas o tags son imprescindibles (WELLER, 2013: 79-94). En definitiva, la web semántica permite optimizar la organización de la información y mejorar la precisión de las búsquedas a través del significado y las relaciones entre los datos, y no solo por su contenido textual.

El interés y la utilidad de la web semántica es lo que me impulsó a formar un grupo de investigación y a dirigir el proyecto «Guerra e historia pública», que estuvo financiado por la Generalitat Valenciana de 2017 a 2019 (AICO2017-011). Quiero destacar su carácter interdisciplinar, ya que establece la colaboración entre especialistas de historia, ingeniería multimedia, turismo, didáctica, patrimonio y filología. El principal resultado fue la web $\mathrm{GeHP}$, diseñada y desarrollada por el ingeniero Juan Luis López Javaloyes (Zurita et al., 2019). Esta plataforma digital ha permitido mejorar la organización de los recursos históricos y la información, facilitar la precisión de las búsquedas mediante el etiquetado semántico de los recursos y la información de geolocalización y, por último, fomentar la navegación entre los diferentes tipos de recursos aumentando la visualización de las relaciones existentes entre ellos. ${ }^{13}$ La web, además, es una revista digital (ISSN 2659-7357), puesto que de forma periódica ofrece nuevos recursos, información histórica sobre la guerra de 1808-1814, así como noticias sobre sus actividades. Cuenta con un comité científico internacional formado por reconocidos especialistas en los campos de la Historia Contemporánea, las Humanidades digitales, el Patrimonio, la Ingeniería multimedia y la Historia pública. Este comité evalúa periódicamente la calidad de la web y hace propuestas para su mejora (Fig. 1).

Dos de los elementos más novedosos, en los que está centrado el proyecto de historia digital, son la creación de recursos y los mapas temáticos georreferenciados. Las rutas históricas también cuentan con un amplio campo de investigación, que detallaré más adelante.

13 Guerra e historia pública, disponible en https://www.guerra-historia-publica.es/ [Consulta: 109-2021]. 


\subsection{Los recursos digitales: características y utilidades}

La creación de recursos tiene como objetivo principal ofrecer diversa información y fuentes sobre la guerra de 1808-1814 organizados en seis tipos: Bienes materiales, Documentos, Hechos, Iconografía, Instituciones y Personajes. ${ }^{14}$ Los recursos cuentan con unos campos obligatorios como el «resumen»-sobre su contenido-, la fecha, las referencias -bibliográfica o de archivo- y, al menos, dos etiquetas -referidas a temas-. El etiquetado de los recursos requiere una revisión, ya que el «muro» generado por aquellas, demasiado cargado, dificulta su lectura y exploración (Fig. 2).

Cada recurso posee diversas características tipológicas. Así, por ejemplo, un «Personaje» especifica el título nobiliario y su profesión; una «Iconografía» permite indicar si es pintura, grabado o medalla conmemorativa; $y$, en el caso de un «Bien material», si se trata de un castillo, un palacio, un puente, una iglesia o un paraje natural. Al final del recurso figura el nombre de la persona que lo ha creado, un aspecto que es importante subrayar, pues evidencia el trabajo colaborativo y la autoridad compartida en la web.

Todos los recursos, salvo los personajes, están geolocalizados y también es posible vincularlos o establecer «relaciones» con otros recursos. Todo ello, enriquece la información ofrecida y permite utilizarlos para investigación, didáctica y turismo. Además, el motor de búsqueda posibilita múltiples selecciones: por tipo de recurso, localización, rango de fechas o nombre. Un ejemplo lo tenemos con el Combate del puente de Villarreal (Castellón) y que vemos en la Fig. 3.

Cuando utilizamos el mapa para buscar los recursos, muestra su icono identificativo y, al situar el ratón sobre uno de ellos, aparece una ventana con el nombre del recurso y un vínculo que lleva al mismo. El ejemplo de Sagunto se puede ver en la Fig. 4.

El trabajo colaborativo resulta esencial en un proyecto de historia pública. No solo es deseable dentro del ámbito académico, entre el profesorado, sino que también hay que organizarlo con el alumnado de Historia y fuera de la Universidad. Desde hace dos años, trabajo en esta línea para ir creando una Comunidad de historia digital en torno al tema de la guerra en la Comunidad Valenciana. Con ello, se garantiza la continuidad del proyecto y su crecimiento. A tal efecto, la web tiene una interfaz, para la creación de recursos, a la que se accede una vez que el usuario se ha registrado y cuenta con la autorización del administrador. La página de inicio cuenta con un sencillo tutorial para familiarizar a los colaboradores en el proceso de creación de los recursos. ${ }^{15}$ Sin duda, este espacio colaborativo requiere la combinación de diversas acciones, puesto que la relevancia de un proyecto de historia digital deriva del hecho de que sea conocido, difundido y utilizado y que, al mismo tiempo, amplíe sus contenidos (SALVATORI, 2017: 189-197).

El elemento más novedoso, y con diversas posibilidades para la transferencia de conocimiento y la didáctica, es el conjunto de recursos geolocalizados, etiquetados y relacionados (MORENO VERA, 2020). El criterio seguido para su creación ha sido su relación con dos coyunturas históricas importantes en territorio valenciano: el levantamiento y las diversas respuestas ante Napoleón entre mayo

14 Explorador de recursos, disponible en [Consulta: 10-9-2021]. 15 «Colabora con nosotros», disponible en https://www.guerra-historia-publica.es/colabora [Consulta: 20-9-2021]. https:/ / www.guerra-historia-publica.es/recursos 
y julio de 1808, y el impacto de la ocupación francesa entre septiembre de 1811 y julio de 1813. Además, el proyecto presta atención a los lugares de la memoria a través de los monumentos y el callejero.

La creación de recursos es posible, sobre todo, gracias a la aportación de voluntarios/as, a falta de una fuente de financiación estable. Por mi parte, aunque participo en esa actividad, sobre todo trabajo en la selección de contenidos y la revisión de los recursos creados por los colaboradores. Al respecto, el módulo de administración de la web establece tres tipos de usuario: editor, autor y colaborador. El primero tiene capacidad para crear, modificar o suprimir recursos propios y ajenos; el segundo sólo puede operar así con sus propios recursos. Los «colaboradores», en fin, únicamente acceden a los recursos creados por ellos mismos, si bien permanecen ocultos -no son públicos- hasta que los visibiliza el editor de la web.

Durante los tres años de existencia de la web, el proyecto ha contado con cerca de 30 colaboradores. La mayoría son o han sido estudiantes del Grado en Historia $\mathrm{y}$, junto al profesorado, quiero destacar la participación de un grupo de seis voluntarios de Almansa, jubilados, que, bajo la coordinación de un Licenciado en Historia y técnico de Cultura del Ayuntamiento, han creado cerca de 40 recursos a partir de la documentación del Archivo municipal. Por otra parte, la colaboración de GeHP con otro proyecto de historia digital como Tablas Martinien -dirigido por Antonio Grajal- permite enriquecer la información sobre el Ejército francés destacado en el antiguo Reino de Valencia. ${ }^{16}$ Se puede ver la lista y el número de recursos que ha hecho cada uno en la sección «Quienes somos».

\subsection{Cartografía dinámica y rutas históricas}

En cuanto a los mapas georreferenciados, por el momento, contamos con uno, que representa la ocupación francesa entre enero de 1812 y julio de 1813. Estas fechas son claves, pues comprenden el período de presencia del Ejército de Aragón en Valencia. El mapa se ha elaborado a partir de la documentación generada por el Estado Mayor del mariscal Suchet y que se encuentra en el Service Historique de la Défense, en Paris. Permite ver la situación de las tropas, por municipios, unidades y fechas, y es el punto de partida para analizar con detalle el control efectivo del territorio. Desde el punto de vista gráfico, se ha combinado el mapa histórico del Atlas de Suchet con el mapa físico y el trabajo de georeferenciación hecho por la empresa Inteligencia Climática, lo que permite la gradación de uno u otro (Fig. 5). ${ }^{17}$

En estos momentos, estamos elaborando un segundo mapa, en colaboración con el proyecto Tablas Martinien (GRAJAL et al., 2020) donde cartografiaremos las bajas sufridas por el Ejército francés en acciones de guerra (muertos, heridos y prisioneros) y por enfermedad (muertos), detallando la unidad a la que pertenecían, así como la fecha y el lugar en el que fueron baja. Ello nos permitirá completar la información del primer mapa y, con ambos, tendremos una detallada radiografía sobre la presencia militar francesa y los costes de la guerra para las tropas napoleónicas en Valencia. Tenemos previsto, a medida que

16 Tablas Martinien disponible en https:/ / www.tablasmartinien.es/\# [Consulta: 10-9-2021].

17 Temas georreferenciados disponible en https://www.guerra-historia-publica.es/guerra-en-valencia/geotemas [Consulta: 10-9-2021]. 
avance la investigación, cartografiar otros temas relevantes para la comprensión de la guerra como pueden ser: el juramento de la Constitución de 1812 en los municipios, las acciones guerrilleras de partidas como las de «El Frare» o Romeu, y las exigencias de suministros de los ejércitos que recorrieron o permanecieron en territorio valenciano.

En un proyecto de historia pública digital es importante la colaboración con la administración local. Y, en este sentido, la elaboración de rutas históricas, concebidas como recurso turístico, ofrece una buena oportunidad. La cultura aparece como una importante motivación para viajar, es uno de los segmentos de demanda que ha experimentado mayor crecimiento en las últimas décadas y, por ello, puede actuar como dinamizador económico. En este caso, la creación de rutas relacionadas con la guerra en Valencia supone una transferencia de conocimiento, de forma especial gracias al diseño de una aplicación para dispositivo móvil que utiliza los recursos de la web (Such y Riquelme, 2020). Por el momento, contamos con cuatro: Alicante, Mutxamel, Castalla y Sax. ${ }^{18}$ Las rutas y los recursos, por último, disponen de un código QR que facilita la didáctica y la creación de museografía nómada.

Termino la explicación de este proyecto con los resultados de una actividad que resultó aleccionadora. En julio de 2020, participé en el Curso de la UIMPSantander titulado: Hacer Historia Contemporánea en tiempos de cultura digital. Modalidades, fuentes, métodos y herramientas. Mi aportación fue una conferencia y un taller sobre «La Historia pública digital». En este último, propuse al alumnado, a modo de caso práctico, que buscase información y recursos en la web sobre un tema de su elección y, sobre todo, que analizase los puntos fuertes y débiles de la plataforma, tanto en lo referido a la experiencia de navegación como en cuanto a los contenidos ofrecidos por ella y sus prestaciones. El resultado fue muy satisfactorio, pues señalaron diversas utilidades y demandaron webs semánticas sobre otros temas históricos.

\section{EL PROYECTO PAISAJES DE GUERRA}

La enriquecedora experiencia del proyecto anterior me animó a profundizar, en el campo de la historia digital, dentro del mismo período histórico, pero con un enfoque más amplio. Así, coordiné el proyecto Web semántica y Patrimonio cultural. Los paisajes y lugares de la Guerra de la Independencia española (PAdGUE), liderado por la Universidad de Alicante y financiado por la Fundación BBVA en su convocatoria de 2018 para equipos de investigación en Humanidades Digitales. ${ }^{19}$

Siguiendo la estela de otros países que, desde hace muchos años, han puesto en valor los bienes patrimoniales relacionados con la guerra, nos planteamos este objetivo para el caso español. Es cierto que la protección de los campos de batalla y su musealización han respondido a criterios de nacionalización política y, en algunos casos, de justificación de la guerra (Mira y ZuRITA, 2020). En nuestro planteamiento, y a la hora de analizar y entender los paisajes, hemos tenido en cuenta esta mirada, pero para generar una reflexión en favor de la paz. El objetivo

18 Rutas GeHP disponible en https://www.guerra-historia-publica.es/rutas/app [Consulta: 11-92021].

19 Fundación BBVA disponible en https://www.fbbva.es/equipo/web-semantica-y-patrimonio-cultural-lospaisajes-y-lugares-de-la-guerra-de-la-independencia-espanola-webpagui/ [Consulta: 1-9-2021]. 
central del proyecto ha sido destacar el valor patrimonial de los paisajes culturales relacionados con las batallas y asedios de la guerra de Independencia en España. Seleccionamos, entonces, trece campos de batalla en función de tres criterios de básicos: las consecuencias de las batallas y sitios en el transcurso de la guerra y su impacto internacional; una larga proyección, en los cien años siguientes, en el ámbito de la construcción del nacionalismo; y, por último, atendimos a su nivel de protección y a la pervivencia, al menos parcial, del paisaje rural, o la perduración de lugares de memoria en los espacios urbanos. Así, investigamos sobre Badajoz, Bailén, Cádiz-Chiclana, Castalla, Girona, La Albuera, Los Arapiles, Sagunto, Somosierra, Tarragona, Valencia, Vitoria y Zaragoza. ${ }^{20}$

Nuestro trabajo tenía además otra importante finalidad: por medio de la divulgación y la transferencia de conocimiento, hemos subrayado que la compresión de la guerra, de sus efectos y representaciones, debe servir para impulsar una cultura de la paz. Para ello, formé un equipo interdisciplinar más extenso que en Guerra e historia pública, con un modelo transmedia de comunicación de los resultados (MoyA, 2020). Así, la difusión de la web semántica y del nuevo contenido generado por reportajes audiovisuales sería impulsado en las redes sociales (Fig. 6).

Identificado con el acrónimo y logo PAdGUE, el proyecto se ha sustentado en la web semántica https://www.patrimonio-paisaje-guerra.es/ diseñada y desarrollada por Carlos Aracil Pérez. En ella, ofrecemos recursos históricos, cartográficos, iconográficos, museográficos y audiovisuales que están geolocalizados, etiquetados y relacionados y que pueden ser usados por aplicaciones para dispositivo móvil. Como en el caso anterior, el apartado Recursos es el más novedoso, en comparación con muchas webs de historia, por su gestión y por los resultados que ofrece. En relación con lo primero, se ha diseñado un panel de administración al que sólo pueden acceder los investigadores y colaboradores con los permisos correspondientes. Una vez dentro, se puede seleccionar la creación de cinco tipos diferentes: documentos, iconografías, personajes, hechos y bienes materiales. Todos ellos tienen campos comunes obligatorios, como título, contenido, referencias... y otros optativos y específicos. La inclusión de una o varias imágenes, las relaciones con otros recursos existentes, la asignación a un campo de batalla y el etiquetado son fundamentales y enriquecen la información.

El espacio público de los Recursos es su Explorador, que pretende ser una de las secciones más potentes de la web. Muestra y geolocaliza información y recursos históricos mediante búsquedas de forma simple o avanzada -hasta ahora, contamos con más de 800 ítems-. Para ello, ofrece filtros que facilitan las búsquedas: por etiquetas, campos de batalla y en función del tipo de recurso. Asimismo, permite visualizar los resultados de la búsqueda en forma de lista o tabla y ordenarlos en base a criterios que dependen del tipo de recurso. El mapa, creado con Open Street Map, y, por tanto, de uso libre y con licencia gratuita, nos muestra de forma genérica la ubicación de los 13 campos de batalla; y, según acercamos el zoom, localiza los recursos, diferenciados por un icono representativo en función de su tipo (Fig. 7).

Junto a los recursos, el segundo elemento novedoso de la web, y en el campo de la historiografía sobre la guerra, es la caracterización de los paisajes culturales en los espacios donde tuvieron lugar las batallas y los sitios. Así, cada uno de los

20 Campos de batalla, disponible en https://www.patrimonio-paisaje-guerra.es/campos-batalla [Consulta: 1-9-2021]. 
escenarios bélicos posee página propia dentro de la web y en ella se muestran: el resumen sobre el paisaje que ha perdurado hasta la actualidad; un mapa con la delimitación del lugar de los combates; un reportaje audiovisual -con una duración media de unos 20-25 minutos- así como otros vídeos cortos grabados por el equipo de investigación; audiovisuales de interés localizados en la red; cartografía y material complementario; y, por último, en la parte inferior, los enlaces a los recursos relacionados con ese campo de batalla. En la Figura 8 vemos el ejemplo de Bailén.

Quiero destacar la importante aportación de 13 reportajes audiovisuales realizados en colaboración con el Taller de Imagen de la Universidad de Alicante. En cada uno, elaboramos un guion en el cual escogimos los aspectos más destacados del hecho bélico y de su memoria y los insertamos en los lugares donde se produjeron y en los espacios públicos donde se han preservado bienes materiales. De ese modo, hemos mostrado los paisajes culturales conformados por esos acontecimientos. Las grabaciones nos llevaron por buena parte de la geografía española y en cada audiovisual combinamos la voz en off con locuciones de los miembros del proyecto y de colaboradores especialistas en la historia local, que no siempre han sido del mundo académico. Varios de estos reportajes han recibido miles de visionados en el canal de Youtube del proyecto (Fig. 9).

La tercera aportación de interés son las Rutas históricas. Con ellas, ofrecemos propuestas para descubrir lugares de memoria y paisajes relacionados con la guerra de la Independencia en España. Estas rutas están nutridas por los recursos geolocalizados -fundamentalmente, Bienes materiales e Iconografía- y, en la web, el grupo de investigación ha creado, hasta ahora, once, para recorrerlas a pie, en bicicleta o en coche/motocicleta. El mapa del itinerario queda ordenado en secuencia de visitas con los recursos a la izquierda; y ofrece, además, la posibilidad de generar un código QR junto con el detalle de los recursos a la derecha (enlace al recurso y resumen breve) y acceder a otros recursos de interés. La generación de los códigos QR, habilitados también en los Recursos, permite crear elementos esenciales para la museografía nómada (Lladó y Atenas, 2010; Llonch, 2010). Al igual que en GeHP, esto es posible gracias al diseño de una App para dispositivo móvil. La Aplicación Rutas PAdGUE (descarga gratuita en Play Store) da acceso a las rutas predefinidas; el usuario, además, en función de su posición geolocalizada, puede crear rutas propias, al seleccionar los recursos disponibles en un determinado radio (5, 10 kilómetros...). ${ }^{21}$ En la Figura 10 vemos la Ruta por el campo de batalla de La Albuera, en Badajoz.

De la misma forma que hicimos en Guerra e historia pública, esta segunda web muestra las entidades colaboradoras y a las personas que han participado en la creación de recursos y en la difusión en redes sociales. El comité científico internacional reúne a especialistas en las distintas áreas de conocimiento que han contribuido a los contenidos de la web, evalúa de forma periódica la calidad de la web y realiza propuestas para su mejora.

21 Rutas PAdGUE disponible en https://www.patrimonio-paisaje-guerra.es/app [Consulta: 26-92021]. 


\section{CONCLUSIONES}

En junio de 2021, se inauguró en el Archivo Histórico Provincial de Alicante la Exposición titulada: Valencianos en guerra, 1808-1814. Permanecerá abierta año y medio y representa la estrecha conexión de los proyectos explicados a lo largo de este artículo. Ante todo, muestra la guerra desde el enfoque de la historia social del conflicto y dedica un espacio a los «campos de batalla: un patrimonio cultural por descubrir». Además, utiliza códigos $\mathrm{QR}$, que dirigen al visitante hacia las dos webs. En ellos, es posible obtener más información sobre hechos, personajes, iconografía o bienes materiales, y también se ven los reportajes audiovisuales creados por PAdGUE sobre los paisajes de guerra valencianos. ${ }^{22}$ Considero que la Exposición supone, en definitiva, un ejemplo de historia pública porque es el resultado de una amplia y variada gama de actividades (CAUVIN, 2020).

Guerra e historia pública, y Paisajes de guerra son dos ejemplos de historia digital que, esperemos, puedan perdurar en internet muchos años. Ya se ha dicho que uno de los principales interrogantes e inquietudes que genera en los creadores es que los contenidos se vuelvan inaccesibles o desaparezcan de la red. Sin embargo, es evidente que, mientras están a disposición del público, las webs semánticas ofrecen diversas utilidades: narración histórica, instrumentos y fuentes para la investigación, recursos para la didáctica, la museografía y el ocio. Si sumamos la generación de códigos QR y las aplicaciones para dispositivo móvil, la puesta en valor del patrimonio y la transferencia de conocimiento resultan evidentes.

La calidad de los contenidos viene avalada no solo por el personal investigador que ha conformado los proyectos, sino también por el respaldo de los comités científicos de las webs. Al mismo tiempo, como se sustentan en el trabajo colaborativo y la autoridad compartida, pueden ser considerados proyectos de historia pública (CAUVIN, 2020: 24-26). Resulta visible en la creación de los recursos -muestran el nombre del/la autor/a- y a través de la participación en los reportajes audiovisuales ofrecidos por PAdGUE. El empeño por la divulgación, generada desde el rigor, es otro de los aspectos que quiero subrayar y es posible, sobre todo en Paisajes de guerra, mediante la presencia en las redes sociales y en el canal de Youtube.

Sin duda, las webs citadas son mejorables y vislumbro que tienen un largo recorrido por delante para incrementar contenidos, llegar a un mayor número de estudiosos, docentes y amantes de la historia, y para ampliar la comunidad de usuarios. Hasta el momento, el balance es positivo y responden a los objetivos que nos trazamos cuando concebimos los proyectos de investigación que estuvieron en su origen. Cabe preguntarse por las ventajas de la historia digital sobre la narrativa convencional en la investigación de la guerra. Creo que, en determinados aspectos, como el tratamiento de algunas fuentes y la comunicación audiovisual, ofrece nuevas miradas que contextualizan e interrelacionan las interpretaciones del período 1808-1814.

Resta hacer una reflexión sobre la aportación historiográfica de ambos proyectos. Resulta difícil saber la repercusión que han tenido porque, por el momento, desconozco citas de las webs en obras impresas o digitales, si bien empieza a ser conocida en el ámbito de las redes sociales y por el profesorado interesado en la didáctica. La guerra de la Independencia española, tras el

22 Exposición Valencianos en guerra, 1808-1814, disponible en https://www.patrimonio-paisajeguerra.es/exposicion [Consulta: 19-9-2021]. 
bicentenario, es un tema que hoy día despierta escaso interés en el mundo académico, pese a que los mitos generados en y por la guerra han tenido notable repercusión en la construcción del nacionalismo español (DEMANGE et al., 2007). Es más, siguen presentes en el espacio público y de forma periódica cobran visibilidad por las iniciativas de los grupos de recreación histórica napoleónica y de algunas administraciones locales. Ante esto, los proyectos plantean un metarrelato en el que se enfatiza el contexto social de la guerra y la necesidad de promover una cultura de la paz frente a la pervivencia de unos mitos que apelan esencialmente a valores belicistas.

\section{REFERENCIAS}

Alía, F.; Pasamar, G.; Bocanegra, L.; Lucci, M.; Guarsch, Y.; Ceamanos, R. (2017): «Ciencia historiográfica, transferencia del conocimiento y humanidades digitales: metodologías de investigación, documentación digital y revistas de historia», en D.A. González, M. Ortiz Heras y J.S. Pérez Garzón (coords.): La Historia lost in translation?, Universidad de Castilla-La Mancha, Albacete: 3.133-3.206.

Ashton, P.M; Trapeznik, A. (2019): What is Public History Globally? Working with the Past in the Present, Bloomsbury, London.

BoCANEGRA BARBECHO, L. (2016): «Las humanidades digitales y el aprendizaje en acceso abierto: el caso de la comunidad sobre Historia Digital», en M. GEA Megías (ed.): Experiencia MOOC: un enfoque hacia el aprendizaje digital, la creación de contenidos docentes y comunidades online, Universidad de Granada, Granada: 155-163.

Bocanegra Barbecho, L.; Toscano, M.; Delgado Anés, L. (2017): «Co-creación, participación y redes sociales para hacer historia. Ciencia con y para la sociedad», Historia y comunicación social, 22 (2): 325-346. https://doi. org/10.5209/HICS.57847

Cauvin, Th. (2020): «Campo nuevo, prácticas viejas: promesas y desafíos de la Historia Pública», Hispania Nova, 1 Extraordinario: 7-51.

Cohen, D.J.; Rosenzwig, R. (2006): Digital History. A guide to gathering, preserving and presenting the Past on the Web, University of Pennsylvania, Philadelphia.

Demange, Ch; Géal, P.; Hocquellet, R; Michonneau, S.; Salgues, M (2007): Sombras de mayo. Mitos y memoria de la Guerra de la Independencia en España (1808-1908), Casa de Velázquez, Madrid.

Grajal de Blas, A.; Planas Campos, J.; Sacristán Donoso, J.M. (2020): «Martinien revisitado. Un proyecto de historia digital», en R. ZuRITA y A. ABвou (coords.): Historia pública de la guerra de 1808-1814, Biblioteca Virtual Miguel de Cervantes, Alicante: 125-169. http://www.cervantesvirtual.com/nd/ ark:/59851/bmc0989819

Lladó Morales, M.; Atenas, J. (2010): «La interactividad y la Web 2.0», en J. Santacana i Mestre y C. Martín Piñol (coords.), Manual de museografía interactiva, Trea, Gijón: 337-368.

Llonch Molina, N. (2010): «Turismo e interactividad. El paradigma del siglo XX», en J. Santacana i Mestre y C. Martín Piñol (coords.), Manual de museografía interactiva, Trea, Gijón: 463-484. 
Mira Rico, J.A.; Zurita Aldeguer, R. (2020): «La gestión de los campos de batalla: una asignatura pendiente en España», en monográfico Historia pública, patrimonio del conflicto y museos, HEREMUS, 21: 77-103. https:/ / doi. org/10.34810/hermusn21id 378124

MorA, H. et al. (2015): «La web semántica como apoyo a la docencia», en M.T. Tortosa Ybáñez, J.D. Álvarez Teruel y N. Pellín Buades (coords.): XIII Jornadas de Redes de Investigación en Docencia Universitaria, Universidad de Alicante, Alicante: 1.912-1.925. Recuperado de http://hdl.handle.net/10045/49521

Moreno VerA, J.R. (2020): «Historia pública y pensamiento histórico. Nuevos enfoques metodológicos para aprender la guerra de la Independencia española», Hispania Nova, 1 Extraordinario: 161-185. https://doi. org/10.20318/hn.2020.5369

MoyA, J.A. (2020): «Comunicación audiovisual de los campos de batalla como recursos culturales: el caso del proyecto PAdGUE», en monográfico Historia pública, patrimonio del conflicto y museos, HEREMUS, 21: 104-115. https:/ / doi. org/10.34810/hermusn2 1id378129

Noiret, S. (2013): «Digital history 2.0», en F. Clavert y S. Noiret (dirs.), L'histoire contemporaine á l'ére numérique, Peter Lang, Bruxelles, Bern-Berlin-Oxford: 155-190.

NoIRET, S. (2018a): «Trabajar con el pasado en internet: la historia pública digital y las narraciones de las redes sociales», Ayer, 110: 111-140.

Noiret, S. (2018b): «Digital Public History», en D. DeAn (ed.), A Companion to Public History, Wiley-Blackwell, Hoboken: 111-124.

PACI, D. (2019): La storia in digitale. Teorie e metodología, Unicopli, Milano.

PONS, A. (2013): El desorden digital. Guía para historiadores y humanistas, Siglo XXI, Madrid.

POns, A.; EIROA, M. (eds.) (2018): «Historia digital: una apuesta del siglo XXI», Ayer, 110: 13-18.

PRADES VILAR, M. (2016): «Escritura, fuentes y demostración en la historia digital: problemas y retos actuales», Revista de Humanidades, 34: 225-259.

SAlvatori, E. (2017a): «Digital (Public) History: la nuova strada di una antica disciplina», Rivista dell'Istituto di Storia dell'Europa Mediterranea, 1: 57-94.

SAlvatori, E. (2017b): «Storia digitale e publica: lo storico tra i nuovi creatori di Storia», en P. Bertella, L. Bertucelli y A. Botti (a cura di): Public History. Discussioni e patriche, Mimesis, Milano: 189-197.

Such Climent, M ${ }^{a}$ P.; Riguelme Quiñonero, Ma T. (2020): «Simbiosis entre Turismo e Historia. La Guerra de la Independencia en la ciudad de Alicante», en R. Zurita y A. Aвbоu (eds.): Historia pública de la guerra de 1808-1814, Biblioteca Virtual Miguel de Cervantes, Alicante: 53-69.

Villagrá, C.; López Javaloyes, J.L. (2020): «La web semántica “Guerra e historia pública" y la transferencia de conocimiento», Hispania Nova, 1 Extraordinario: 81-113. https:/ / doi.org/10.20318/hn.2020.5367

Weller, T. (2013): History in the Digital Age, Routledge, London-New York.

Zurita Aldeguer, R. (2015): Suchet en España. Guerra y sociedad en las tierras del sur valenciano (1812-1814), Ministerio de Defensa, Madrid.

Zurita, R.; Hernando, P.; Laspra, A.; LóPez, J.L.; Such, P.; Moreno, J.R.; Villagrá, C. (2019): «Web semántica y transferencia de conocimiento. Un proyecto sobre didáctica de la guerra y turismo cultural», en M. Moreno SECO (coord.): Del siglo XIX al XXI. Tendencias y debates. Actas del XIV Congreso de la AHC, 
Biblioteca Virtual Miguel de Cervantes, Alicante: 297-313. http:/ / hdl.handle. net $/ 10045 / 95805$

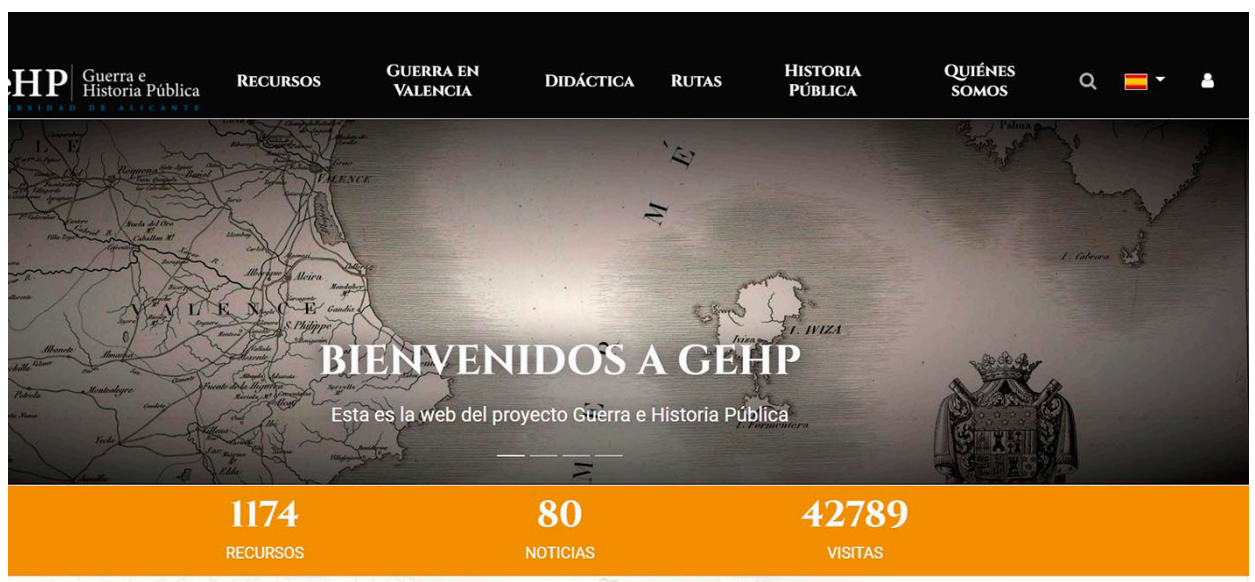

Figura 1. Página de inicio de la web GeHP. Guerra e Historia pública Fuente: Universidad de Alicante. https:// www.guerra-historia-publica.es. Consulta: 27-9-2021.

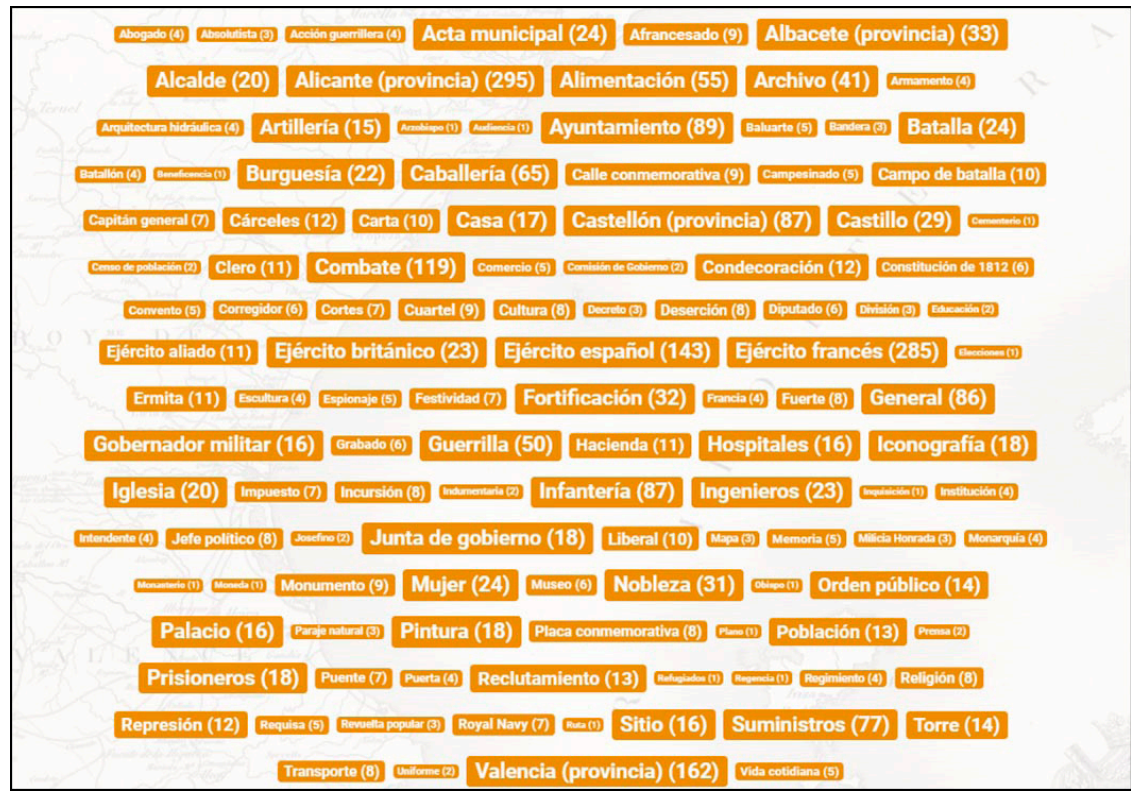

Figura 2. «Explora por etiquetas». Web GeHP. Guerra e Historia pública. Fuente: Universidad de Alicante. https:// www.guerra-historia-publica.es/recursos. Consulta: 30-7-2021. 
Guerra de la Independencia e historia digital

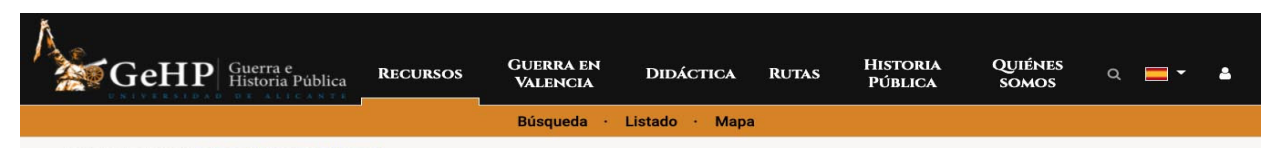

Combate del puente de Villarreal

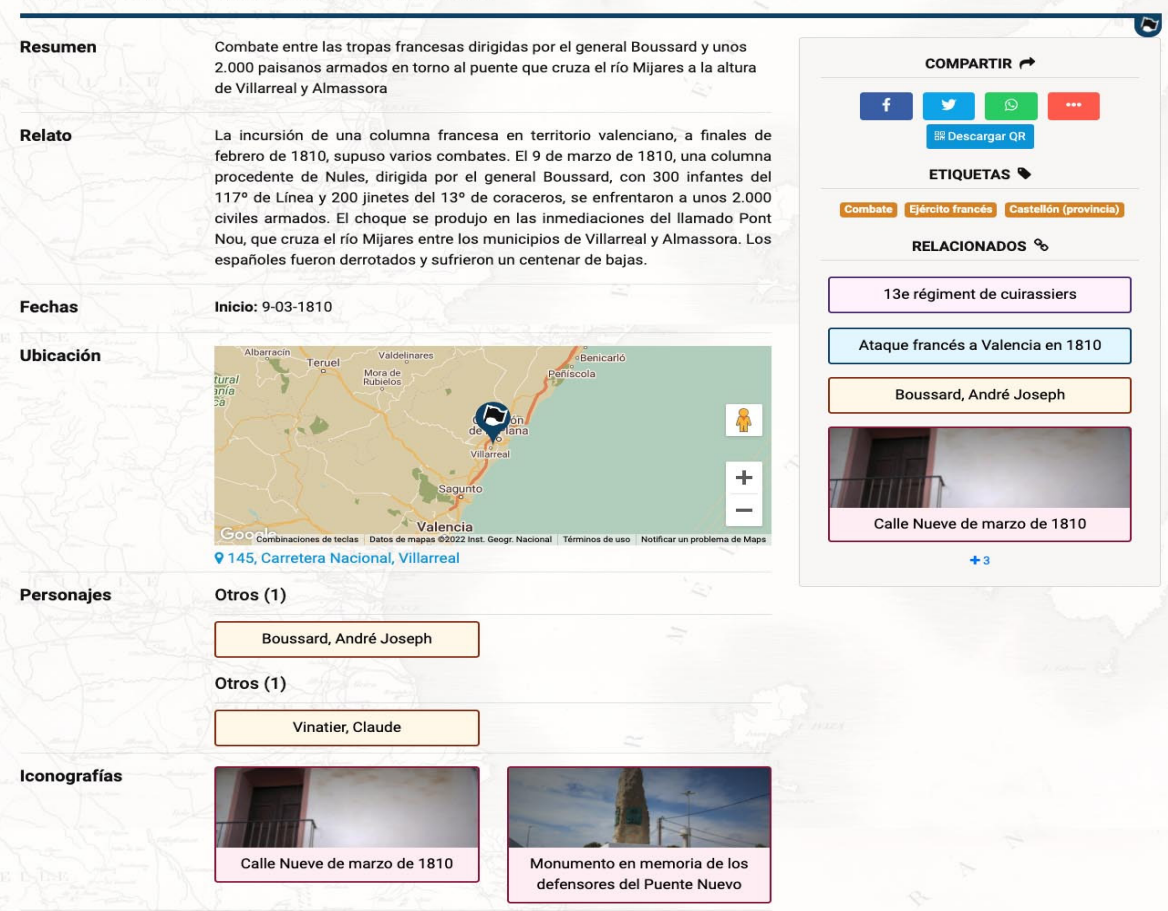

\footnotetext{
Bienes materiales

(6)

Pont Nou sobre Puente construido entre 1784 y 1790 entre los el río Mijares

términos municipales de Villarreal y Almazora

von?
Instituciones
(ii)
13 e régiment de cuirassiers
13e régiment de cuirassiers
Ataque francés a El 5 de marzo de 1810, el general Suchet se presentó ante Valencia en 1810 la cludad de Valencia y envió una intimidación para exigir
Hechos
relacionados su rendición

Referencias

1. Pardo Camacho, R. (2009). La Guerra de la Independencia en Castellón. Castellón de la Plana: Aula Militar "Bermúdez de Castro". pp. 9-10.

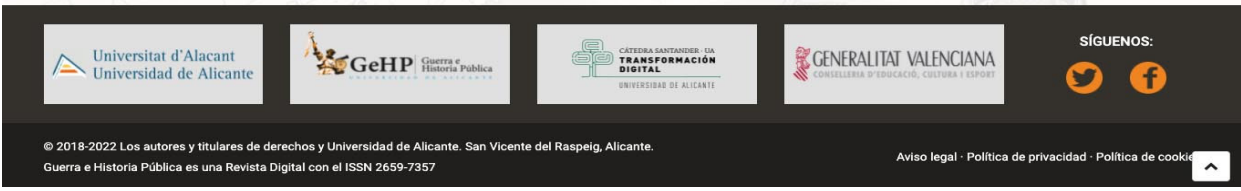

Figura 3. Captura de la web GeHP. Guerra e Historia pública. Recurso «Combate del puente de Villarreal». Fuente: Universidad de Alicante. https:/ / www.guerra-historiapublica.es/recursos/1065. Consulta: 30-7-2021. 


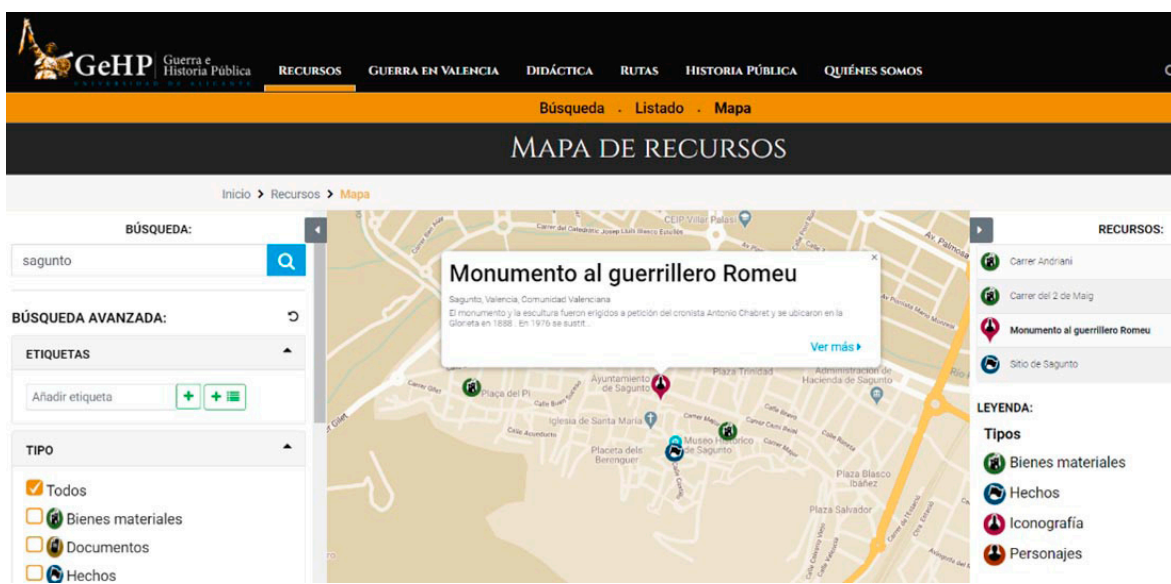

Figura 4. Captura de la web GeHP. Guerra e Historia pública. «Sagunto». Recursos geolocalizados. Fuente: Universidad de Alicante https:// www.guerra-historia-publica. es/recursos. Consulta: 30-7-2021.

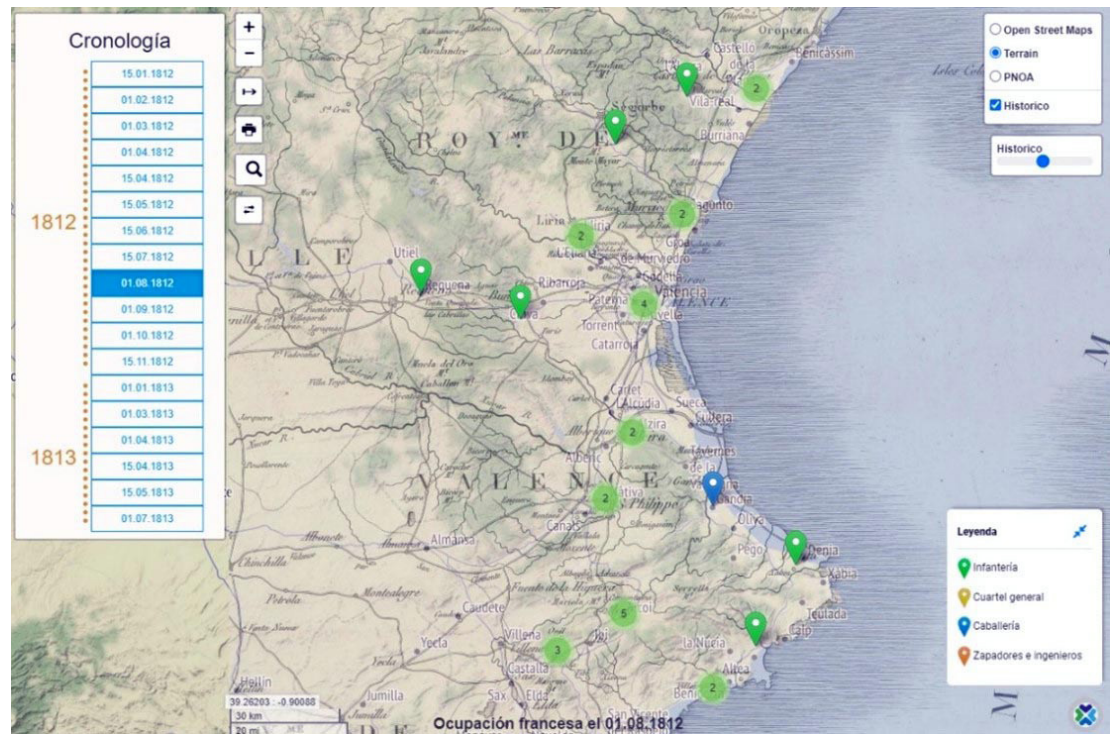

Figura 5. Captura de pantalla de la web GeHP. Guerra e Historia pública. Mapa georreferenciado con la distribución de la ocupación francés el 1-8-1812. Fuente: Universidad de Alicante https:/ / www.guerra-historia-publica.es/guerra-en-valencia/ geotemas. Consulta: 14-9-2021. 

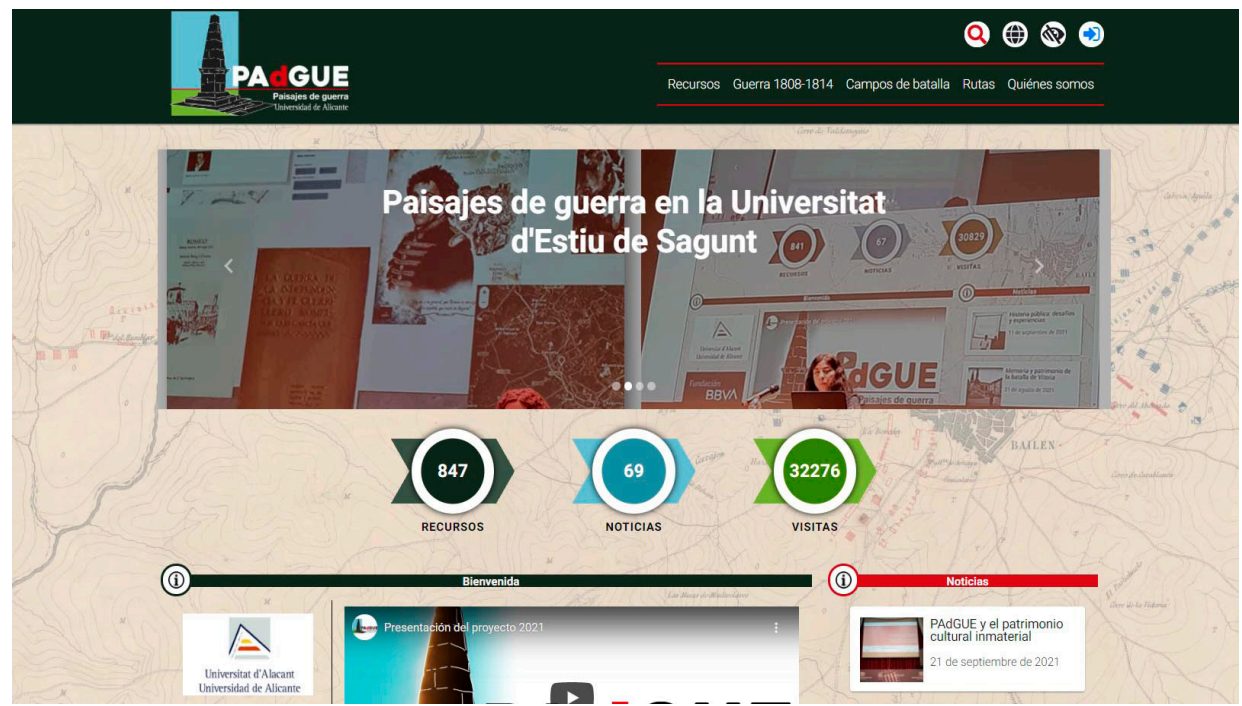

Figura 6. Captura de pantalla de la página de inicio de la web «Paisajes de guerra». Fuente: Universidad de Alicante. https://www.patrimonio-paisaje-guerra.es/recursos/ mapa. Consulta: 27-9-2021.

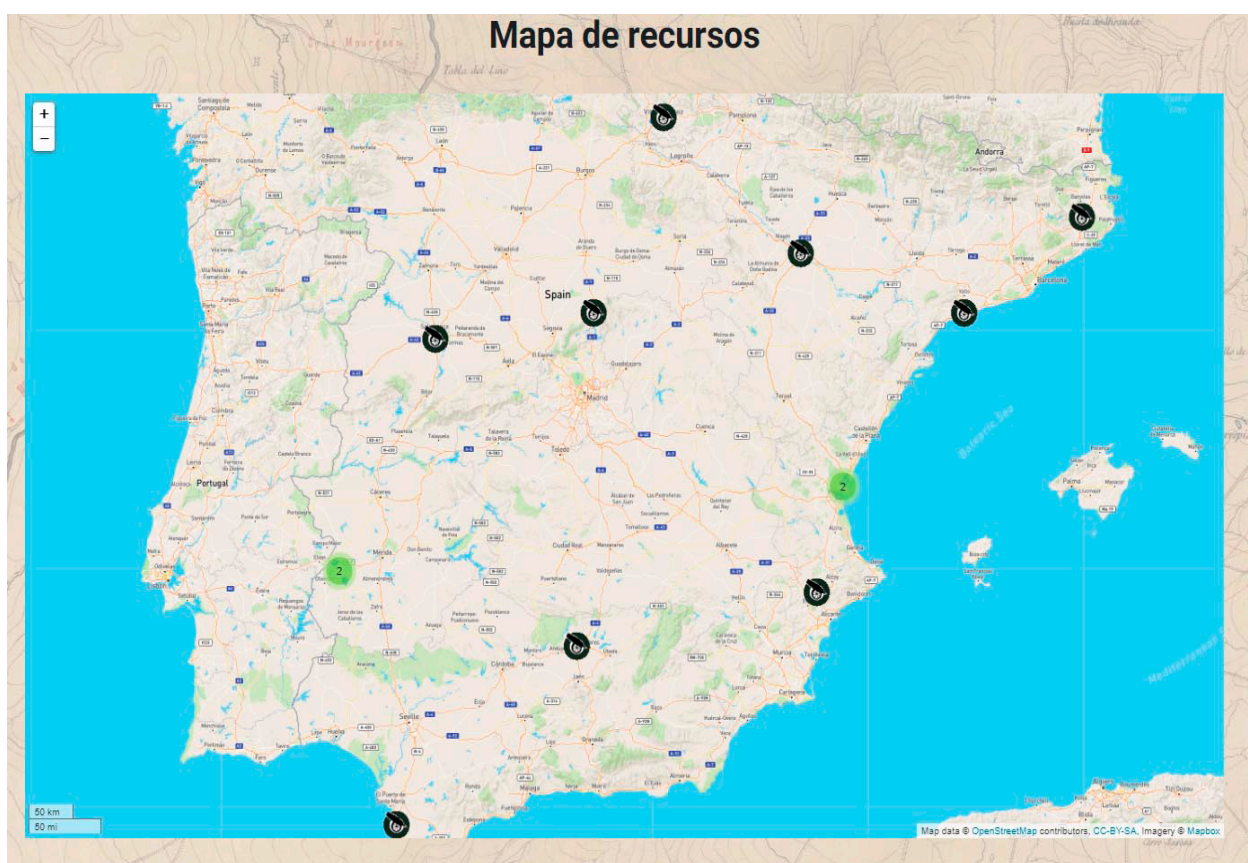

Figura 7. Captura del apartado Mapa. Muestra la delimitación de los campos de batalla y la localización de los recursos. Fuente: Universidad de Alicante. https:/ / www. patrimonio-paisaje-guerra.es/recursos/mapa. Consulta: 24-9-2021. 


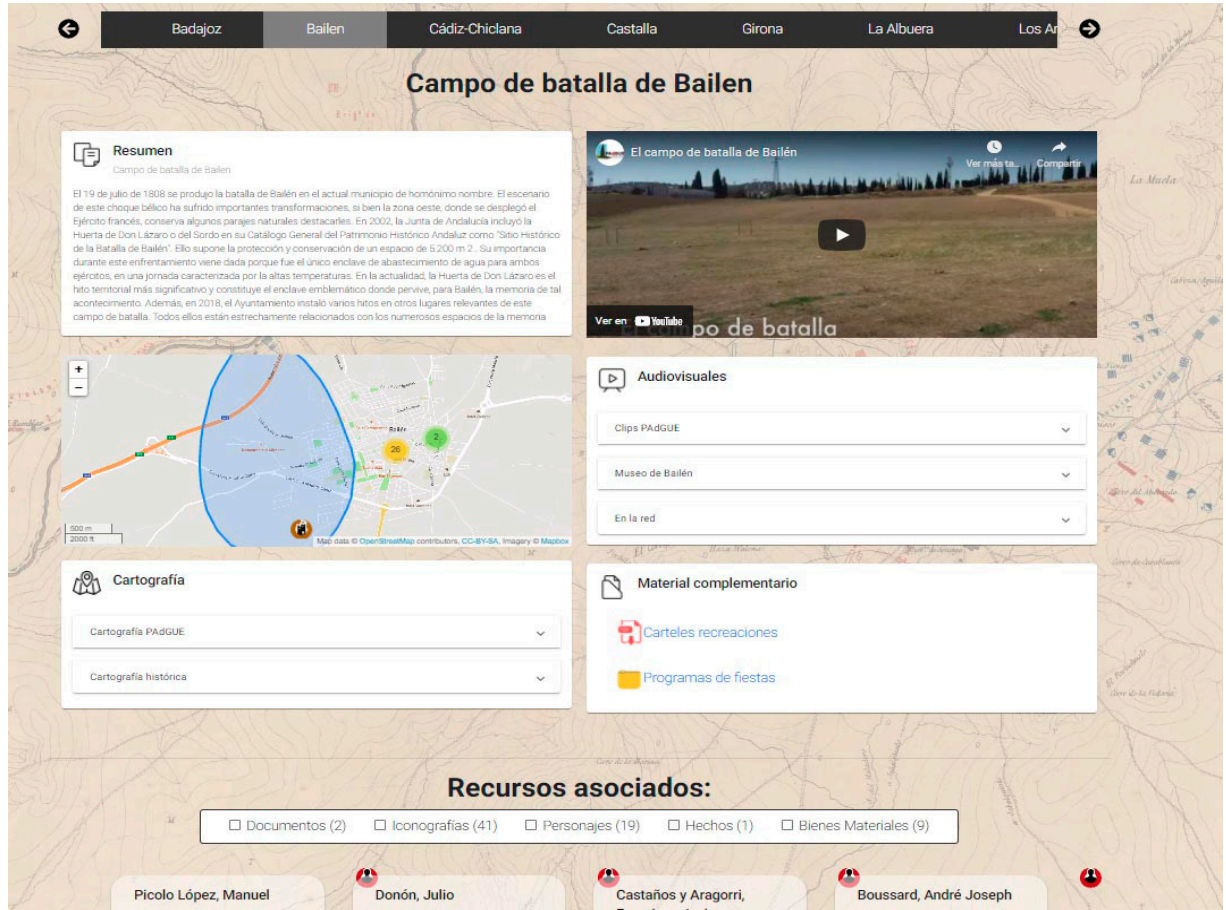

Figura 8. Captura de la página Campo de batalla de Bailén.

Fuente: Universidad de Alicante. https://www.patrimonio-paisaje-guerra.es/camposbatalla/_k35oe8oe5oppp. Consulta: 24-9-2021.

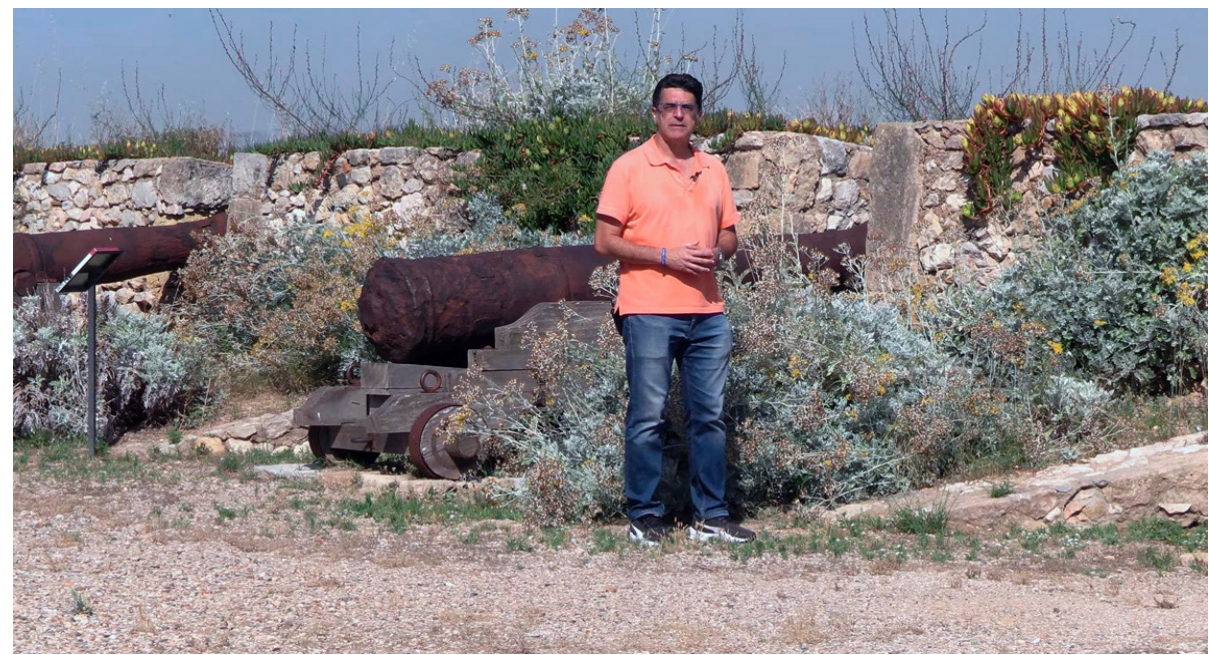

Figura 9. Captura del reportaje sobre el campo de batalla de Tarragona

Fuente: Universidad de Alicante. https:// www.patrimonio-paisaje-guerra.es/camposbatalla/_k38oe8oe5oyyy. Consulta: 24-9-2021. 
Guerra de la Independencia e historia digital

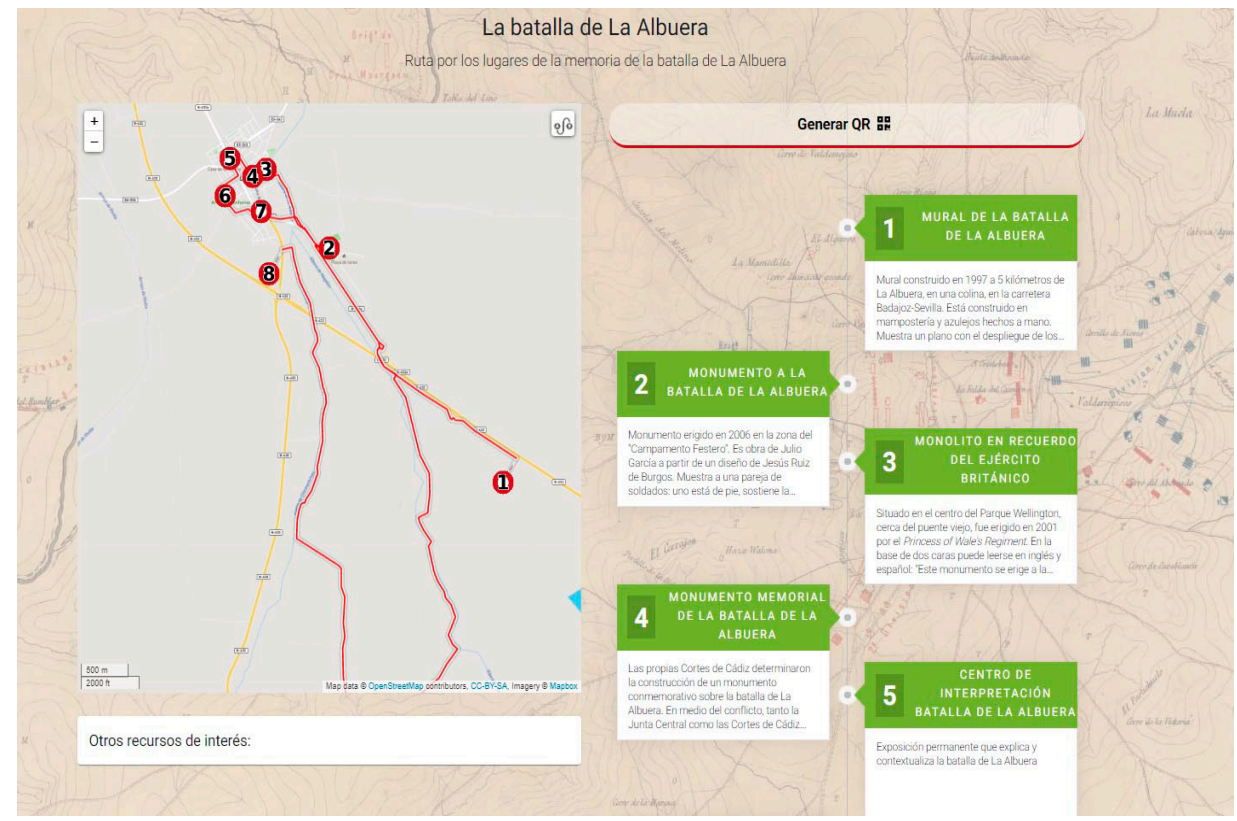

Figura 10. Captura de la página Ruta La batalla de La Albuera. Fuente: Universidad de Alicante. https://www.patrimonio-paisaje-guerra.es/rutas/ver-rutas/_kkp4aq5zp4aq5. Consulta: 24-9-2021. 